\title{
Prophylactic Intrawound Application of Vancomycin Powder in Instrumented Spinal Fusion Surgery
}

\author{
Hyun Su Kim, Sang Gu Lee, Woo Kyung Kim, Chan Woo Park, Seong Son \\ Department of Neurosurgery, Gachon University Gil Medical Center, Incheon, Korea
}

\begin{abstract}
Objective: We evaluated the effect of intrawound application of vancomycin powder for infection prophylaxis in wounds caused by instrumented spinal surgery.

Methods: From July 2012 to December 2012, 74 instrumented spinal fusion procedures were performed by 1 neurosurgeon at a single institute. We divided the patients into 2 groups, depending on the use of local application of vancomycin powder: Group A (intrawound application of vancomycin powder with perioperative intravenous cefazolin) and Group B (perioperative intravenous cefazolin alone). A retrospective cohort comparative study was conducted between the 2 groups. The age, sex, comorbidities, smoking, surgical procedure, and surgical site infection (SSI) of consecutive patients were analyzed.

Results: Among the 74 patients, 34 patients were assigned to group A and 40 patients to group B. No wound infections were found in group A. However, in group B, 5 cases of SSI (12.5\%) were found. A statistically significant reduction in SSI incidence was observed in group A $(p<0.033)$. The 5 cases of SSI in group B consisted of 3 cases of deep wound infection and 2 cases of superficial wound infection. All SSIs were found in cases of posterior approach surgery and tended to be more frequent in older patients.

Conclusion: Adjunctive intrawound local application of vancomycin powder is a simple uncomplicated procedure and can result in a significant reduction of SSI in instrumented spinal fusions. Furthermore, culture of the drainage tip is very important for confirmation of deep wound infection.
\end{abstract}

Key Words: Wound infection $\cdot$ Spine $\cdot$ Instrumentation $\cdot$ Vancomycin

\section{INTRODUCTION}

Despite the use of prophylactic systemic antibiotics and improved surgical techniques, surgical site infection (SSI) is still a serious, challenging postoperative complication. Such infections often require additional surgery, prolonged administration of systemic antibiotics, delayed rehabilitation, and increased medical costs. Therefore, they have a profound impact on patients. In addition, mortality risk is doubled in patients with SSI ${ }^{12)}$.

To reduce the incidence of infection, local application of antibiotics is an attractive option because high concentrations are achieved directly at these sites and systemic toxicity is limited ${ }^{6,7,14}$. In the only human study of prophylactic local

\footnotetext{
- Received: April 2, 2013 • Revised: July 27, 2013

- Accepted: July 29, 2013

Corresponding Author: Sang Gu Lee, MD, PhD

Department of Neurosurgery, Gachon University Gil Medical Center

1198 block, Guweol-Dong, Namdong-Gu, Incheon 405-220, Korea

Tel: +82-32-460-3304, Fax: +82-32-460-3899

E-mail: samddal@gilhospital.com
}

antibiotics, the addition of vancomycin powder to standard systemic prophylaxis in elective spine surgery reduced infection rates from $2.6 \%$ to $0.2 \%{ }^{27}$. In addition, no specific adverse events were reported, and no differences in radiographic outcomes was found between groups ${ }^{5,27)}$.

The authors aimed to determine the effect of local application of vancomycin powder on reducing the infection rate among patients undergoing instrumented posterior spinal fusion, by comparing patients who did and did not receive local application of vancomycin powder at the surgical site, in addition to standard intravenous (IV) antibiotic prophylaxis.

\section{MATERIALS AND METHODS}

\section{Study setting and Patient Enrollment}

From July 2012 to December 2012, 74 consecutive cervi$\mathrm{cal}$, thoracic, and lumbar instrumented spinal fusions were performed by 1 surgeon at a single institute.

From July 2012 to October 2012, all patients received standard systemic antibiotic prophylaxis consisting of $1 \mathrm{~g} \mathrm{IV}$ 
cefazolin within 1 hour of surgical incision followed by $1 \mathrm{~g}$ IV cefazolin every 8 hours for 1 day. All patients who underwent spinal instrumented fusion surgery in or after October 2012 received an additional application of $1 \mathrm{~g}$ of vancomycin powder spread throughout the surgical wound.

Patients who had undergone elective spinal fusion using pedicle screw and rod instrumentation at any level for treatment of spinal instability were included. Patients with a previous history of spinal instrumented surgery and infections at the surgical site were excluded.

We divided the patients into 2 groups depending on the use of local application of $1 \mathrm{~g}$ vancomycin powder: Group A (additional local vancomycin powder used) and Group B (local vancomycin powder not used).

All patients underwent preoperative preparation with alcohol followed by betadine solution.

Before closing the wound, $1 \mathrm{~g}$ of vancomycin powder was directly applied on the muscle, fascia, and subcutaneous tissues after ensuring that the bone graft or dura mater was not exposed.

The wounds were closed with absorbable sutures for the fascia and subcutaneous layers and with staples for the skin. After skin closure, the incisions were cleaned again with alcohol and betadine solution, and a sterile dressing was applied.

A drain was kept in place until the drainage volume was less than $30 \mathrm{cc}$, and the dressing was maintained daily until the stitches were removed (usually 7 days).

The clinical demographics (age and gender), data on coexisting chronic diseases (diabetes, hypertension, and tuberculosis), history of tobacco use, and operative time for each patient were retrospectively obtained from clinical chart reports. The estimated blood loss (EBL), number of levels fused, and drain maintenance period were also obtained from the operative chart.

The primary outcome was the incidence of SSI. We classified SSI according to 2 types: deep SSI and superficial SSI. Deep SSI was confirmed by culture results of the drainage line tip, and superficial SSI was confirmed by the results of swab culture of surgical wound discharge. When SSI was discovered in a patient, cultured organisms and subsequent treatments were recorded.

\section{Statistical Analysis}

All retrieved data were converted into categorical or binominal variables. Chi squared test, 1 -way analysis of variance (ANOVA), logistic regression analysis, multiple regression analysis, t-test, and Cox regression analysis were used for assessment of statistical relationships. Statistical significance was accepted at a p-value of $<0.05$.

\section{RESULTS}

Seventy-four patients were included in the study. Group A included 34 patients, and group B included 40 patients. Overall, the groups were similar with regard to baseline characteristics (Table 1). The general surgical variables between the 2 groups are described in Table 2. The operative level, approach methods, disease entity, and operative parameters (operation time, EBL, transfusion volume, and duration of drainage) of the 2 groups were similar, and no statistical differences were found between the 2 groups, except for infection rate. No infections (0\%) occurred in group A, whereas 5 surgical infections (12.5\%), including 3 deep wound and 2 superficial wound infections occurred in group $B$; this difference was found to be statistically significant $(p=0.033)$ using Fisher's exact test. An additional statistical analysis for relative risk (RR) is shown in Table 3. This analysis revealed that the RR for infection in the control group was 1.143 times higher than that in the vancomycin group, which was found to be statistically significant (95\% confidence interval, 1.017-1.285).

All SSIs were found in cases of posterior approach surgery, but this was not statistically significant $(\mathrm{p}=0.176)$. Methicillin-resistant coagulase-negative staphylococcus (MRCNS) was cultured from 2 of the 3 deep SSIs, and Acinetobacter baumannii was cultured from the third SSI. Two cases of methicillinsensitive Staphylococcus aureus (MSSA) were found in the superficial SSIs. All SSIs occurred primarily in elderly patients. In our study, in contrast to common conventions, diabetes $(p=0.178)$ and smoking history $(p=0.147)$ were not associated with the occurrence of infection. Treatments used for patients with SSIs are described in Table 4.

No adverse effects were attributable to local application

Table 1. General clinical variables of the groups

\begin{tabular}{llcc}
\hline \hline & & $\begin{array}{c}\text { Vancomycin group } \\
(\mathrm{n}=34)\end{array}$ & $\begin{array}{c}\text { Control group } \\
(\mathrm{n}=40)\end{array}$ \\
\hline Age & & $57.88 \pm 13.38$ & $60.05 \pm 11.19$ \\
Gender & Male & 21 & 17 \\
& Female & 13 & 23 \\
Comorbidities & HTN & 12 & 18 \\
& DM & 3 & 8 \\
& Tbc & 4 & 2 \\
Tobacco use & Yes & 14 & 8 \\
& No & 20 & 32 \\
\hline
\end{tabular}

HTN, hypertension; DM, diabetes mellitus; Tbc, tuberculosis of vancomycin powder. 
Table 2. Characteristics of instrumented surgery

\begin{tabular}{|c|c|c|c|c|}
\hline \multirow{2}{*}{\multicolumn{2}{|c|}{$\begin{array}{l}\text { Operative Level } \\
\end{array}$}} & \multirow[t]{2}{*}{ Vancomycin group $(n=34)$} & \multirow[t]{2}{*}{ Control group $(n=40)$} & \multirow[t]{2}{*}{ p-value } \\
\hline & & & & \\
\hline \multirow{3}{*}{ Cervical } & 1 level & $2(15.4)$ & $5(27.8)$ & \multirow{5}{*}{0.176} \\
\hline & 2 level & $8(61.5)$ & $4(22.2)$ & \\
\hline & 3 level & $1(7.7)$ & $3(16.7)$ & \\
\hline \multirow{6}{*}{ Thoracic } & multiple (>3 level) & $2(15.4)$ & $6(33.3)$ & \\
\hline & 1 level & $0(0.0)$ & $0(0.0)$ & \\
\hline & 2 level & $1(16.7)$ & $2(33.3)$ & \multirow{3}{*}{0.717} \\
\hline & 3 level & $2(33.3)$ & $1(16.7)$ & \\
\hline & multiple (>3 level) & $3(50.0)$ & $3(50.0)$ & \\
\hline & 1 level & 11 (73.3) & $4(25.0)$ & \multirow{4}{*}{0.135} \\
\hline \multirow{3}{*}{ Lumbar } & 2 level & $4(26.7)$ & $8(50.0)$ & \\
\hline & 3 level & $0(0.0)$ & $3(18.8)$ & \\
\hline & multiple (>3 level) & $0(0.0)$ & $1(6.3)$ & \\
\hline \multicolumn{5}{|c|}{ Approach } \\
\hline & Anterior & $11(32.4)$ & $16(40.0)$ & \multirow[t]{3}{*}{0.555} \\
\hline & Posterior & $18(52.9)$ & $21(52.5)$ & \\
\hline & Lateral & $5(14.7)$ & $3(7.5)$ & \\
\hline \multicolumn{5}{|c|}{ Disease entity } \\
\hline \multicolumn{2}{|c|}{ Previous operative history } & 1 & 0 & \multirow[t]{4}{*}{0.205} \\
\hline & & 3 & 2 & \\
\hline & & 7 & 9 & \\
\hline \multicolumn{2}{|c|}{ Degenerative Disease } & 23 & 29 & \\
\hline \multicolumn{2}{|c|}{ Operation time (Hour) } & 6.5 & 7.16 & 0.099 \\
\hline \multicolumn{2}{|l|}{ EBL (ml) } & 651.47 & 827.5 & 0.165 \\
\hline \multicolumn{2}{|c|}{ Transfusion volume (ml) } & 200 & 303.75 & 0.225 \\
\hline \multicolumn{2}{|l|}{ Infection } & $0(0.0 \%)$ & $5(12.5 \%)$ & $0.033^{*}$ \\
\hline
\end{tabular}

EBL, estimated blood loss ${ }^{*} p<0.05$

Table 3. Relative risk of infection with and without administration of vancomycin

\begin{tabular}{lccccc}
\hline \hline & & \multicolumn{2}{c}{ Infection } & \multirow{2}{*}{ Total } & $\begin{array}{c}\text { Relative } \\
\text { risk }\end{array}$ \\
\cline { 3 - 4 } & No & Yes & & 34 & \multirow{2}{*}{ Vancomycin } \\
\multirow{2}{*}{ Total } & Yes & 34 & 0 & 34 \\
& No & 35 & 5 & 40 & \\
\hline
\end{tabular}

(95\% confidence interval, 1.017-1.285)

\section{DISCUSSION}

Postoperative deep wound infection after instrumented spinal fusion is a significant complication with an unexpected worsening clinical outcome. Prophylaxis with IV cephalosporin provides coverage for less than 50\% of the Staphylococcus organisms found in hospitals and is probably not an adequate prophylactic agent by itself ${ }^{13,19)}$. However, IV vancomycin does not reduce SSI rates either ${ }^{18,25)}$, and administration of IV vancomycin is associated with several side effects, including hypotension, renal toxicity, and the development of resistant organisms ${ }^{17}$.

To reduce the rate of infection, the use of local antibiotics in addition to IV antibiotics has been suggested ${ }^{1,2,3,4,23,24)}$. Local delivery of antibiotics is an attractive option because high concentrations are achieved directly at surgical wound sites and systemic toxicity is limited ${ }^{6,714)}$. Thus, antibiotics are delivered where they are needed the most. This rationale is well accepted in the treatment of established infections and has recently been investigated as a means of prophylaxis rather than treatment.

Several related studies have reported the pharmacokinetics of locally applied antibiotic powder; however, the standard goal of local pharmacokinetics remains undetermined. In 2011, Sweet et al. reported the local pharmacokinetics of vancomycin powder ${ }^{27}$. Their study showed that very high doses 
Table 4. Patients with postoperative infection from the control group

\begin{tabular}{|c|c|c|c|c|c|c|c|c|c|}
\hline Patient & $\begin{array}{l}\text { Sex/ } \\
\text { Age }\end{array}$ & Diagnosis & $\begin{array}{l}\begin{array}{l}\text { Fusion } \\
\text { levels }\end{array} \\
\end{array}$ & Approach & $\begin{array}{c}\text { Tobacco } \\
\text { History (P/Y) }\end{array}$ & Diabetes & $\begin{array}{l}\text { Infection } \\
\text { type }\end{array}$ & $\begin{array}{c}\text { Culture (site, } \\
\text { organism) }\end{array}$ & Treatment \\
\hline 1 & M/75 & OPLL C4-5 & C3-6 & Posterior & $O(30)$ & $x$ & Deep & $\begin{array}{l}\text { Drain tip } \\
\text { MRCNS }\end{array}$ & $\begin{array}{l}\text { Local wound care } \\
\text { vancomycin and } \\
\text { colistin }\end{array}$ \\
\hline 2 & M/77 & $\begin{array}{l}\text { Fracture dislocation } \\
\text { C6 on C7 } \\
\text { Cervical spinal cord } \\
\text { injury } \\
\text { Spinous process } \\
\text { Fracture C5 } \\
\text { Lamina Fracture } \\
\text { C6 Right }\end{array}$ & C3-T1 & Posterior & $x$ & $x$ & Deep & $\begin{array}{l}\text { Drain tip } \\
\text { MRCNS }\end{array}$ & $\begin{array}{l}\text { Local wound care } \\
\text { vancomycin and } \\
\text { teicoplanin }\end{array}$ \\
\hline 3 & M/76 & $\begin{array}{l}\text { Metastatic tumor } \\
\quad \text { T4, L1 }\end{array}$ & T2-6 & Posterior & $x$ & $x$ & Deep & $\begin{array}{l}\text { Drain tip } \\
\text { Acinetobacter } \\
\text { baumannii }\end{array}$ & $\begin{array}{l}\text { Local wound care } \\
\text { amikacin and } \\
\text { tazobactam }\end{array}$ \\
\hline 4 & $\mathrm{~F} / 72$ & $\begin{array}{l}\text { HCD C34, 45, } \\
56,67\end{array}$ & C3-6 & Posterior & $\bigcirc(3)$ & $x$ & Superficial & $\begin{array}{l}\text { Swab culture } \\
\text { MSSA }\end{array}$ & cefazolin \\
\hline 5 & $M / 44$ & $\begin{array}{l}\text { Scoliosis, } \\
\quad \text { HLD L34, } 45\end{array}$ & L3-5 & Posterior & $x$ & $\bigcirc$ & Superficial & $\begin{array}{l}\text { Swab culture } \\
\text { MSSA }\end{array}$ & cefazolin \\
\hline
\end{tabular}

MRCNS, methicillin-resistant coagulase-negative staphylococci; MSSA, methicillin-sensitive Staphylococcus aureus

of vancomycin were achieved in the local environment, with drug levels up to a 1,000-fold higher than the mean inhibitory concentration for methicillin-resistant $S$. aureus and coagulase-negative staphylococcus. Local application of vancomycin powder into the surgical wound produced wound drug levels of $128-1,457 \mathrm{\mu g} / \mathrm{mL}$, several fold higher than those documented with vancomycin elution from bone cement $(15 \mathrm{\mu g} / \mathrm{mL})$. This concentration of vancomycin may provide a super-bactericidal effect in the local environment.

Several studies have reported the effect of local antibiotic powder. Kevin et al. reported a significantly lower incidence of postoperative surgical wound infections through the use of local vancomycin powder in patients undergoing posterior spinal stabilization for traumatic injuries ${ }^{20)}$. The infection rate of $13 \%$ in the control group is in agreement with previous studies in this population ${ }^{22)}$. No infections were found in the group treated with vancomycin powder in the surgical wound. This infection rate is consistent with that reported in a previous study of locally applied vancomycin powder for infection prophylaxis, which found that the infection rate decreased from $2.6 \%$ to $0.2 \%$ in patients undergoing elective spinal fusions ${ }^{27}$. Similarly, results of our study show a significant difference between the treatment (vancomycin powder) and control groups. There was no occurrence of infection in the treatment group, whereas 5 infections (12.5\%) occurred in the control group. The group with local vancomycin powder treatment showed no infections, which was statistically different when compared with the infection rate in the group with no use of local vancomycin powder $(\mathrm{p}=0.033)$.

Some studies have reported that high concentrations of antibiotics inhibit bone healing in vitro, ${ }^{5,-11,16,15,21)}$. In an animal model, the peak concentration of gentamicin after application of powder briefly exceeds the threshold for affecting osteoblasts $^{10,26}$. However, it is unclear whether this would have a significant effect on bone healing or fusion. In the only human study of prophylactic vancomycin powder usage, concentrations were found to be well below the threshold concentration estimated to inhibit osteoblasts in vitro, and no difference was found in radiographic outcomes ${ }^{2,5,27)}$.

This study has several limitations. First, this study was conducted in a retrospective fashion. Therefore, selective bias and confounding factors were likely present. In addition, not all factors known to contribute to postoperative infections were evaluated. Information on factors that contribute to infection, such as limited mobility, malnutrition, obesity, and various medical comorbidities could not be obtained in a retrospective fashion. The available data were insufficient for comparison of nutrition markers. Another limitation is that a relatively small number of patients were evaluated. Finally, the local pharmacokinetics (such as the local concentration and dose) achieved using the method described in our study remains undetermined. Future studies are needed to determine the minimally effective local concentration and to standardize the treatment dose of vancomycin. 


\section{CONCLUSION}

In our study, the use of local vancomycin powder resulted in a significant decrease in the occurrence of postoperative infections in patients undergoing instrumented spinal fusion surgery. No adverse side effects were attributable to the local vancomycin powder. Additional prospective and large-volume studies are needed to further substantiate the effectiveness of this prophylactic method for reduction of postoperative spinal SSIs using a simple application of local vancomycin powder. Furthermore, culture of the drainage tip is very important for confirming the microorganisms present in deep wound infection; the results of culture facilitate selection of antibiotic treatment for postoperative infections.

\section{REFERENCES}

1. Borkhuu B, Borowski A, Shah SA, Littleton AG, Dabnet KW, Miller F: Antibiotic-loaded allograft decreases the rate of acute deep wound infection after spinal fusion in cerebral palsy. Spine 33(21):2300-2304, 2008

2. Buttaro M, Comba F, Piccaluga F: Vancomycin supplemented cancellous bone allografts in hip revision surgery. Clin Orthop Relat Res 461:74-80, 2007

3. Buttaro M, Gimenez MI, Greco G, Barcan L, Piccaluga F: High active local levels of vancomycin without nephrotoxicity released from impacted bone allografts in 20 revision hip arthroplasties. Acta Orthop 76(3):336-340, 2005

4. Chen CE, Ko JY, Pan CC: Results of vancomycin impregnated cancellous bone grafting for infected tibial nonunion. Arch Orthop Trauma Surg 125(6):369-375, 2005

5. Edin ML, Miclau T, Lester GE, Lindsey RW, Dahners LE: Effect of cefazolin and vancomycin on osteoblasts in vitro. Clin Orthop Relat Res (333):245-251, 1996

6. Hanssen $\mathrm{AD}$ : Local antibiotic delivery vehicles in the treatment of musculoskeletal infection. Clin Orthop Relat Res (437):91-96, 2005

7. Hanssen AD, Osmon DR, Patel R: Local antibiotic delivery systems: where are we and where are we going? Clin Orthop Relat $\operatorname{Res}(437): 111-114,2005$

8. Holtom PD, Pavkovic SA, Bravos PD, Patzakis MJ, Shepherd LE, Frenkel B: Inhibitory effects of the quinolone antibiotics trovafloxacin, ciprofloxacin, and levofloxacin on osteoblastic cells in vitro. J Orthop Res 18(5):721-727, 2000

9. Huddleston PM, Steckelberg JM, Hanssen AD, Rouse MS, Bolander ME, Patel R: Ciprofloxacin inhibition of experimental fracture healing. J Bone Joint Surg Am 82(2):161-173, 2000

10. Isefuku S, Joyner CJ, Simpson AH: Gentamicin may have an adverse effect on osteogenesis. J Orthop Trauma 17(3):212-216, 2003

11. Isefuku S, Joyner CJ, Simpson AH: Toxic effect of rifampicin on human osteoblast-like cells. J Orthop Res 19(5):950-954, 2001
12. Kirkland KB, Briggs JP, Trivette SL, Wikinson WE, Sexton DJ: The impact of surgical-site infections in the 1990s: attributable mortality, excess length of hospitalization, and extra costs. Infect Control Hosp Epidemiol 20(11):725-730, 1999

13. Klevens RM, Morrison MA, Nadle J, Petit S, Gershman K, Ray $\mathrm{S}$, et al: Invasive methicillin resistant Staphylococcus aureus infections in the United States. JAMA 298(15):1763-1770, 2007

14. Martin C, Viviand X, Potie F: Local antibiotic prophylaxis in surgery. Infect Control Hosp Epidemiol 17(8):539-544, 1996

15. Miclau T, Edin ML, Lester GE, Lindsey RW, Dahners LE: Bone toxicity of locally applied aminoglycosides. J Orthop Trauma 9(5):401-406, 1995

16. Miclau T, Edin ML, Lester GE, Lindsey RW, Dahners LE: Effect of ciprofloxacin on the proliferation of osteoblast-like MG-63 human osteosarcoma cells in vitro. J Orthop Res 16(4):509-512, 1998

17. Moise PA, Smyth DS, El-Fawal N, Robinson DA, Holden PN, Forrest A, et al: Microbiological effects of prior vancomycin use in patients with methicillin-resistant Staphylococcus aureus bacteremia. J Antimicrob Chemother 61(1):85-90, 2008

18. Neoh HM, Hori S, Komatsu M, Oguri T, Takeuchi F, Cui L, et al: Impact of reduced vancomycin susceptibility on the therapeutic outcome of MRSA bloodstream infections. Ann Clin Microbiol Antimicrob 30:6-13, 2007

19. Noskin GA, Rubin RJ, Schentag JJ, Kluytmans J, Hedblom EC, Jacobson C, et al: National trends in Staphylococcus aureus infection rates: impact on economic burden and mortality over a 6year period (1998-2003). Clin Infect Dis 45(9):1132-1140, 2007

20. O'Neill KR, Smith JG, Abtahi AM, Archer KR, Spengler DM, McGirt MJ, et al: Reduced surgical site infections in patients undergoing posterior spinal stabilization of traumatic injuries using vancomycin powder. Spine J 11(7):641-646, 2011

21. Perry AC, Prpa B, Rouse MS, Piper KE, Hanssen AD, Steckelberg JM, et al: Levofloxacin and trovafloxacin inhibition of experimental fracture-healing. Clin Orthop Relat Res (414):95-100, 2003

22. Rechtine GR, Bono PL, Cahill D, Bolesta MJ, Chrin AM: Postoperative wound infection after instrumentation of thoracic and lumbar fractures. J Orthop Trauma 15(8):566-569, 2001

23. Sakaguchi H, Marui A, Hirose K, Nomura T, Arai Y, Bir SC, et al: Less invasive and highly effective method for preventing methicillin-resistant Staphylococcus aureus graft infection by local sustained release of vancomycin. J Thorac Cardiovasc Surg 135(1):25-31, 2008

24. Scharfenberger A, Clark M, Lavole G, O'Connor G, Masson E, Beaupre LA: Treatment of an infected total hip replacement with the PROSTALAC System. Part 1: Infection resolution. Can J Surg 50(1):24-28, 2007

25. Soriano A, Marco F, Martinex JA, Pisos E, Almela M, Dimova $\mathrm{VP}$, et al: Influence of vancomycin minimum inhibitory concentration on the treatment of methicillin-resistant Staphylococcus aureus bactermia. Clin Infect Dis 46(2):193-200, 2008

26. Stall AC, Becker E, Ludwig SC, Gelb D, Poelstra KA: Reduction of postoperative spinal implant infection using gentamicin microspheres. Spine 34(5):479-483, 2009

27. Sweet FS, Roh M, Sliva C: Intra-wound application of vancomycin for prophylaxis in instrumented thoracolumbar fusions: efficacy, Drug levels, and patient outcomes. Spine 15:2084-2088, 2011 